\title{
Editorial
}

\section{Mechanisms of Aspirin-Intolerant Asthma: Identifying Inflammatory Pathways in the Pathogenesis of Asthma}

\author{
Helen Neighbour \\ Divisions of Clinical Immunology and Allergy/Respirology, Department of Medicine, McMaster University, \\ Hamilton, Ont., Canada
}

Asthma is a disease that is associated with considerable morbidity, and still has an associated mortality. Corticosteroids remain the main effective treatment for asthma, but these are associated with potentially serious side effects. Identification of inflammatory pathways in the pathogenesis of asthma allows new therapeutic targets to be proposed.

There is a subset of patients with asthma who experience an exacerbation of their asthma when they take aspirin, so-called aspirin-intolerant asthma (AIA). The association between aspirin and asthma has been known since 1922 when it was first described by Widal [1]; however, it only received widespread recognition in the 1960s when Samter and Beers [2] published the association between asthma, nasal polyps and aspirin sensitivity, subsequently referred to as Samter's triad. The recognition of aspirin-sensitive asthma has significant implications for patient management, as patients with AIA are more likely to have more severe disease and to develop irreversible airflow obstruction.

The mechanism of AIA is due to effects on the metabolism of arachidonic acid. Arachidonic acid is a component of cell walls and is released by the action of cytosolic phospholipase $\mathrm{A}_{2}$. Arachidonic acid can then be metabolized through the cyclooxygenase (COX) pathway to form prostanoids or through the 5-liopoxygenase (5-LO)

\section{KARGER}

E-Mail karger@karger.com

www.karger.com/iaa pathway to form the leukotriene, $\mathrm{LTA}_{4}$. $\mathrm{LTA}_{4}$ is an unstable compound and is rapidly metabolized to either $\mathrm{LTB}_{4}$ or the cysteinyl leukotrienes (CysLTs). The CysLTs are leukocyte chemoattractants and bronchoconstrictors. In addition to COX and 5-LO pathways, 15-lipoxygenase catalyzes the hydroperoxidation of arachidonic acid to form 15-HPETE which is then further metabolized to form 15-HETE and the lipoxins and eoxins. Aspirin causes irreversible inhibition of COX-1 and competes directly with arachidonic acid for binding to the COX site. The proposed mechanism of AIA is the generation of increased levels of CysLTs as a result of increased levels of precursors due the inhibition of COX by aspirin.

Eosinophils generate large amounts of CysLTs, and the appearance of increased levels of eosinophils in the bronchial musosa has been observed in AIA [3]. It has also previously been shown that that activated sputum eosinophils from subjects with AIA produce increased levels of CysLTs ex vivo [4]. This is the first data that define the release of arachidonic acid metabolites from blood eosinophils from well-characterized subjects with AIA. In addition, the responses of normal subjects and differing severities of asthma were studied, allowing the effect of dose of inhaled steroid to be investigated.

Much attention has been paid to the biological role of 5 -LO, but relatively little is known about $15-\mathrm{LO}$ and its
(C) 2013 S. Karger AG, Basel

$1018-2438 / 14 / 1631-0001 \$ 39.50 / 0$
Correspondence to: Dr. Helen Neighbour

Divisions of Clinical Immunology and Allergy/Respirology Department of Medicine, McMaster University

Building St. Joseph's Healthcare, Hamilton, ON L8N 4A6 (Canada)

E-Mail neighbh@mcmaster.ca 
metabolic products. Increased amounts of 15-LO have been found in the bronchial submucosa of patients with asthma [5]. Increased amounts of 15-HETE are also found in asthmatics, and levels of 15-HETE have been associated with pulmonary eosinophilia [6]. It has been shown that the 15 -LO pathway can generate the proinflammatory eoxins in eosinophils, mast cells and nasal polyps from allergic subjects [7]. It has been shown that 15-HETE production in the peripheral blood leukocytes from aspirin-intolerant asthmatics is different from that in aspirin-tolerant asthmatics [8]. The study presented by James et al. [9] further refines this study by isolating eosinophils from the peripheral blood leukocytes and identifying differences in patients with AIA. It has also been shown that the 15-HETE released from nasal polyps obtained from aspirin-sensitive individuals does not cause activation of eosinophils and/or mast cells [10]. The eoxins, however, may be involved in the recruitment of inflammatory cells that are then activated by alternative mechanisms. The current study demonstrated the production of these agents by eosinophils [9]; however, further study is required of the ongoing biological effects of the mediators produced by $15-\mathrm{LO}$.

This study had well-characterized groups of patients with appropriate controls. This included 2 separate groups, those with mild-to-moderate asthma and those with more severe disease to allow the study of the effect of asthma severity. The patients in the severe asthma and AIA asthma groups had higher levels of blood eosinophils and higher $\mathrm{F}_{\mathrm{E}} \mathrm{NO}$ than the other groups; this indicates higher levels of inflammation. Unfortunately, this study does not have full laboratory control analyses. In some subjects, it was possible to isolate only enough eosinophils to perform the analysis of eiscosanoid stimulation, and there were insufficient cells to perform an unstimualted assay. Therefore it is not possible to draw conclusions as to whether aspirin alone could lead to the release of mediators from eosinophils.

The data presented here do have implications for future therapies. Antileukotriene drugs can either be inhibitors of leukotriene synthesis or antagonists of leukotriene receptors. An example of a leukotriene receptor antagonist is montelukast, shown to be an effective treatment for asthma [11]. To activate 5-LO, 5-lipoxygenase activating protein (FLAP) is necessary, and hence drugs have been targeted against FLAP. FLAP antagonists have proved promising in early-phase clinical trials but they have not been developed [12].

Based on the data presented here by James et al. [9], it appears that the 15-LO pathway is a potential therapeutic target for AIA and severe aspirin-tolerant asthma. Based on the known biological effects of 15-HETE, it is reasonable to hypothesize that inhibition of 15-LO may reduce inflammatory cell influx and hence lead to improved control in more severe asthma. The study of mechanisms of AIA asthma will allow for novel therapeutic targets to be identified.

\section{References}

$>1$ Widal F, Abrami P, Lermoyez J: First complete description of the aspirin idiosyncrasyasthma-nasal polyposis syndrome (plus urticaria) - 1922 (with a note on aspirin desensitization). J Asthma 1987;24:297-300.

2 Samter M, Beers RF Jr: Intolerance to aspirin. Clinical studies and consideration of its pathogenesis. Ann Intern Med 1968;68:975983.

3 Sladek K, Dworski R, Soja J, Sheller JR, Nizankowska E, Oates JA, Szczeklik A: Eicosanoids in bronchoalveolar lavage fluid of aspirin-intolerant patients with asthma after aspirin challenge. Am J Respir Crit Care Med 1994;149:940-946.

4 Gaber F, Daham K, Higashi A, Higashi N, Gulich A, Delin I, James A, Skedinger M, Gyllfors P, Nord M, Dahlen SE, Kumlin M, Dahlen B: Increased levels of cysteinyl-leukotrienes in saliva, induced sputum, urine and blood from patients with aspirin-intolerant asthma. Tho$\operatorname{rax} 2008 ; 63: 1076-1082$.
5 Shannon VR, Chanez P, Bousquet J, Holtzman MJ: Histochemical evidence for induction of arachidonate 15-lipoxygenase in airway disease. Am Rev Respir Dis 1993;147:1024-1028.

-6 Chu HW, Balzar S, Westcott JY, Trudeau JB, Sun Y, Conrad DJ, Wenzel SE: Expression and activation of 15-lipoxygenase pathway in severe asthma: relationship to eosinophilic phenotype and collagen deposition. Clin Exp Allergy 2002;32:1558-1565.

7 Feltenmark S, Gautam N, Brunnstrom A Griffiths W, Backman L, Edenius C, Lindbom L, Bjorkholm M, Claesson HE: Eoxins are proinflammatory arachidonic acid metabolites produced via the 15-lipoxygenase-1 pathway in human eosinophils and mast cells. Proc Natl Acad Sci USA 2008;105:680-685.

$>8$ Kowalski ML, Ptasinska A, Bienkiewicz B, Pawliczak R, DuBuske L: Differential effects of aspirin and misoprostol on 15-hydroxyeicosatetraenoic acid generation by leukocytes from aspirin-sensitive asthmatic patients. J Allergy Clin Immunol 2003;112:505-512. $\checkmark 9$ James A, Daham K, Backman L, Brunnström A, Tingvall T, Kumlin M, Edenius C, Dahlén S-E, Dahlén B, Claesson H-E: The Influence of aspirin on release of eoxin $\mathrm{C} 4$, leukotriene C4 and 15-HETE, in eosinophilic granulocytes isolated from patients with asthma. Int Arch Allergy Immunol 2013;162:37-44.

10 Lewandowska-Polak A, Jedrzejczak-Czechowicz M, Makowska JS, Jarzebska M, Jankowski A, Kowalski ML: Lack of association between aspirin-triggered 15-hydroxyeicosatetraenoic acid release and mast cell/eosinophil activation in nasal polyps from aspirin-sensitive patients. J Investig Allergol Clin Immunol 2011;21:507-513.

11 Nayak A: A review of montelukast in the treatment of asthma and allergic rhinitis. Expert Opin Pharmacother 2004;5:679-686.

12 Evans JF, Ferguson AD, Mosley RT, Hutchinson JH: What's all the FLAP about?: 5-lipoxygenase-activating protein inhibitors for inflammatory diseases. Trends Pharmacol Sci 2008;29:72-78. 